\title{
Prognostic value of a novel glycolysis-related gene expression signature for gastrointestinal cancer in the Asian population
}

\author{
Rong Xia ${ }^{1,2 \dagger}$, Hua Tang ${ }^{3 \dagger}$, Jiemiao Shen ${ }^{1,2 \dagger}$, Shuyu Xu ${ }^{1,2}$, Yinyin Liang ${ }^{1,2}$, Yuxin Zhang ${ }^{4}$, Xing Gong ${ }^{1,2}$, Yue Min ${ }^{1,2}$,
}

Di Zhang ${ }^{1,2}$, Chenzhe Tao ${ }^{1,2}$, Shoulin Wang ${ }^{1,2}$, Yi Zhang ${ }^{5^{*}}$, Jinyou Yang ${ }^{6 *}$ and Chao Wang ${ }^{1,2^{*}}$ (D)

\begin{abstract}
Background: Globally, gastrointestinal (Gl) cancer is one of the most prevalent malignant tumors. However, studies have not established glycolysis-related gene signatures that can be used to construct accurate prognostic models for $\mathrm{Gl}$ cancers in the Asian population. Herein, we aimed at establishing a novel glycolysis-related gene expression signature to predict the prognosis of $\mathrm{Gl}$ cancers.
\end{abstract}

Methods: First, we evaluated the mRNA expression profiles and the corresponding clinical data of 296 Asian Gl cancer patients in The Cancer Genome Atlas (TCGA) database (TCGA-LIHC, TCGA-STAD, TCGA-ESCA, TCGA-PAAD, TCGA-COAD, TCGA-CHOL and TCGA-READ). Differentially expressed mRNAs between Gl tumors and normal tissues were investigated. Gene Set Enrichment Analysis (GSEA) was performed to identify glycolysis-related genes. Then, univariate, LASSO regression and multivariate Cox regression analyses were performed to establish a key prognostic glycolysis-related gene expression signature. The Kaplan-Meier and receiver operating characteristic (ROC) curves were used to evaluate the efficiency and accuracy of survival prediction. Finally, a risk score to predict the prognosis of $\mathrm{Gl}$ cancers was calculated and validated using the TCGA data sets. Furthermore, this risk score was verified in two Gene Expression Omnibus (GEO) data sets (GSE116174 and GSE84433) and in 28 pairs of tissue samples.

Results: Prognosis-related genes (NUP85, HAX1, GNPDA1, HDLBP and GPD1) among the differentially expressed glycolysis-related genes were screened and identified. The five-gene expression signature was used to assign patients into high- and low-risk groups $(p<0.05)$ and it showed a satisfactory prognostic value for overall survival $\left(\mathrm{OS}, p=6.383 \times 10^{-6}\right)$. The ROC curve analysis revealed that this model has a high sensitivity and specificity $(0.757$ at 5 years). Besides, stratification analysis showed that the prognostic value of the five-gene signature was independent of other clinical characteristics, and it could markedly discriminate between Gl tumor tissues and normal tissues.

\footnotetext{
*Correspondence: yizhang311@njmu.edu.cn; yangjinyou4518@163.com; wangchao@njmu.edu.cn

${ }^{\dagger}$ Rong Xia, Hua Tang and Jiemiao Shen contributed equally to this work

1 Key Lab of Modern Toxicology of Ministry of Education, Center

for Global Health, School of Public Health, Nanjing Medical University, 101

Longmian Avenue, Nanjing 211166, People's Republic of China

${ }^{5}$ Department of Colorectal Surgery, the First Affiliated Hospital of Nanjing

Medical University, Nanjing 210000, People's Republic of China

${ }^{6}$ Department of Clinical Medicine and Rehabilitation, Jiangsu College

of Nursing, 9 Keji Road, Huai'an 223005, People's Republic of China

Full list of author information is available at the end of the article
}

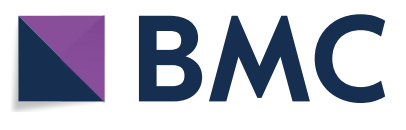

(c) The Author(s) 2021. This article is licensed under a Creative Commons Attribution 4.0 International License, which permits use, sharing, adaptation, distribution and reproduction in any medium or format, as long as you give appropriate credit to the original author(s) and the source, provide a link to the Creative Commons licence, and indicate if changes were made. The images or other third party material in this article are included in the article's Creative Commons licence, unless indicated otherwise in a credit line to the material. If material is not included in the article's Creative Commons licence and your intended use is not permitted by statutory regulation or exceeds the permitted use, you will need to obtain permission directly from the copyright holder. To view a copy of this licence, visit http://creativeco mmons.org/licenses/by/4.0/. The Creative Commons Public Domain Dedication waiver (http://creativecommons.org/publicdomain/ zero/1.0/) applies to the data made available in this article, unless otherwise stated in a credit line to the data. 
Finally, the expression levels of the five prognosis-related genes in the clinical tissue samples were consistent with the results from the TCGA data sets.

Conclusions: Based on the five glycolysis-related genes (NUP85, HAX1, GNPDA1, HDLBP and GPD1), and in combination with clinical characteristics, this model can independently predict the OS of Gl cancers in Asian patients.

Keywords: Gastrointestinal cancer, Glycolysis-related genes, Prognosis, Asian patients

\section{Background}

Globally, cancers of the gastrointestinal (GI) tract, including those that originate from cells in the esophagus, stomach, exocrine pancreas, liver, gallbladder, biliary tract, small intestines, colon, rectum and anus, are associated with a high prevalence and mortality rate [1]. The prevalence of GI cancers, such as liver and gastric cancers, in Asia is higher than in North America or Europe [2]. The pathogenic factors for GI cancer are complex and include chronic inflammation, infection, environmental carcinogens and genetic susceptibility [3]. Currently, the main therapeutic options for GI cancers are surgical resection, radiotherapy and chemotherapy among others. However, the postoperative survival rate is still low [4]. Currently, the prognosis of GI cancer patients relies on traditionally recognized prognostic factors, such as pathological staging, histological grade and immunohistochemical studies of molecular markers [5]. Prognostic indicators are of great significance in developing new treatment strategies, therefore, independent indicators for better prognosis should be urgently established.

The tumor microenvironment is highly involved in the occurrence and development of malignant tumors, and is closely associated with energy metabolism. Mitochondrial oxidative phosphorylation and glycolysis are the two major pathways for cellular energy production [6]. Compared to normal cells, even under normoxia conditions, cancer cells mainly rely on glycolysis to produce the energy required for cellular processes [7]. This phenomenon is regarded as a landmark event in the process of tumor formation. Glycolysis and its related genes play a very essential role in the development of GI cancers [8]. Glucose metabolism, including glycolysis and hexosamine synthesis, is abnormally activated in liver cancer, leading to enhanced malignant phenotypes [9]. Moreover, in gastric cancer, the energy needs of tumor cells are achieved through glycolysis [10]. Enhanced glycolysis has also been shown to promote the proliferation and metastasis of colorectal cancer cells [11]. Currently, the mechanisms through which key enzymes and glycolysis-related genes in tumor metabolic pathways are regulated have not been elucidated. Therefore, elucidating the mechanisms through which metabolic remodeling occurs in tumors is of great clinical significance for the accurate diagnosis and treatment of GI cancers. So far, prognostic prediction models based on glycolytic genes have only been reported in liver and colon cancers [12, 13]. For the first time, we established a risk prediction model that is based on glycolytic genes for seven common tumors of the digestive tract to assist in identifying risky patients and follow-up to improve treatment outcomes in the Asian population.

In recent years, various risk prediction models that are based on gene expression data, such as autophagy-related genes prognosis prediction models [14], immune-related genes prognosis prediction models [15] and inflammation-related genes prognosis prediction models [16], are widely applied in the clinical prediction of patient survival. Elevating aerobic glycolysis and dependence on glycolysis to produce energy is one of the main metabolic characteristics of cancer [17]. Attempts have been made to target tumors by inhibiting the activity of key enzymes in the tumor glycolytic pathway. It has been reported that inhibiting the glycolytic pathway in tumors can effectively suppress the proliferation of tumor cells, and even play a role in killing tumor cells [18]. However, inhibition of a single target may be insufficient in suppressing tumor proliferation and may even cause drug resistance. For example, NRF2 has dual roles in cancer $[19,20]$. The antioxidant function of NRF2 is important in protecting against cancer initiation and progression. Based on such a protective effect, numerous chemopreventive compounds that can activate NRF2 have been identified [21-23]. Besides, NRF2 can also exert cancer-promoting effects [24]. Several NRF2 target genes are involved in drug resistance [22]. Elevated NRF2 levels have been correlated with chemoresistance in cancer cells [20, 25-28]. In addition, the KRAS oncogene, a critical driver of multiple cancers, is also an important target for cancer therapy. Studies have reported that oncogenic KRAS alters glucose and glutamine metabolism to support pancreatic ductal adenocarcinoma cell proliferation [29-32]. KRAS upregulates stress-granule formation, which is involved in chemoresistance [32-34]. Because of the multiple functions of a single gene, it is insufficient to target gene for cancer therapy. Therefore, the therapeutic potential of combined treatment and predictors of multiple glycolytic enzyme targets should be studied [35]. In this study, we aimed at elucidating the relationship between glycolysis-related genes and clinical-related indicators from 
the entire Asian GI tumor, and to establish a more accurate prognostic model that is based on glycolysis-related genes. From the Cancer Genome Atlas (TCGA) database, we identified a glycolytic associated five-gene signature that is closely related to overall survival (OS) of GI cancer patients in the Asian population. Based these five genes, a prognostic prediction model was constructed and was shown to accurately predict and monitor the prognosis for GI cancers in the Asian population.

\section{Methods}

\section{Data collection and mRNA expression dataset}

The mRNA expression profiles and the corresponding clinical data for 296 Asian GI cancer patients were obtained from the TCGA database (http://cancergeno me.nih.gov/). These patients were; 158 LIHC patients, 74 STAD patients, 38 ESCA patients, 11 PAAD patients, 11 COAD patients, $3 \mathrm{CHOL}$ patients and 1 READ patients (TCGA-LIHC, TCGA-STAD, TCGA-ESCA, TCGAPAAD, TCGA-COAD, TCGA-CHOL and TCGA-READ). Their detailed clinical information is summarized in Table 1. Various glycolysis-related genes were obtained from Molecular Signatures Database v7.0 (MSigDB) (https ://software.broadinstitute.org/gsea/msigdb/index.jsp).

\section{Gene set enrichment analysis (GSEA)}

GSEA analysis was performed using the GSEA software v4.0.1 and "h.all.v7.1.symbols.gmt" (http://www.broad institute.org/gsea) to evaluate whether the defined gene sets showed statistically significant differences between the tumor and normal tissues. $p \leq 0.05$ and false discovery rate $(F D R)<0.25$ were the criteria for identifying significantly enriched gene sets in GSEA.

\section{Prognostic signature construction}

Raw mRNA expression data were normalized by [log2 $($ data +1$)$ ] for further statistical analysis. Univariate Cox regression was used to screen and analyze the genes affecting the OS of patients $(p<0.05)$. Then, LASSO Cox regression and multivariate Cox proportional hazards regression models were used to identify and analyze the prognostic genes in order to establish a predictive model. The selected mRNAs were classified into two types; hazard ratio $(\mathrm{HR})>1$ was the risk type while hazard ratio $(\mathrm{HR})<1$ was the protective type. Based on the mRNA expression and coefficients as derived from the multivariate Cox proportional hazards regression analysis, a prognostic risk score formula was established. The risk score formula was: Risk score $=$ expression of gene $_{1} \times \beta_{1}$ gene $_{1}+$ expression of gene $_{2} \times \beta_{2}$ gene $_{2}+\ldots$ expression of gene $_{n} \times \beta_{n}$ gene $_{n}$ ( $\beta$ represents the regression coefficient of each mRNA).
Sample collection and validation of the expression of glycolysis-related genes at mRNA and protein levels The Institutional Review Board of Nanjing Medical University and the Ethical committee of the Tongling People's Hospital approved this study (ethical review No. 2019-008). All study participants were required to sign an informed consent before enrollment. Twenty-eight paired GI tumors and adjacent non-tumor tissues were collected from patients at the Tongling People's Hospital from 2018 to 2019 . All the patients had not received chemotherapy or radiotherapy before surgery. The obtained tissues included 8 paired COAD tissues, 5 paired READ tissues and 15 paired STAD tissues. All tissue samples were rapidly frozen and stored in liquid nitrogen until RNA extraction. Total RNA was extracted and subjected to reverse transcription followed by Real-time quantitative polymerase chain reactions (qRT-PCR), as previously described [36]. The primer sequences were: The forward primer for GAPDH was CCTTCCGTGTCCCCACT while its reverse primer was GCCTGCTTCACCACC TTC; the forward primer for NUP85 was CATTGAGCG GATACCTCTG while its reverse primer was GACGGC TTTCATGGCTAA; The forward primer for GPD1 was TCTTTGGGGAGCAGGAAC while its reverse primer was GAAGGAAGCCTGGGTGAA; the forward primer for HAX1 was GGCTTGCTTTCCGGTAG while its reverse primer was ACGCGAACCTTTGAACC; the forward primer for GNPDA1 was GCAACAGACACTGCC ACA while its reverse primer was CAGGAGAGCGGG $\mathrm{ACACT}$; and, the forward primer for HDLBP was ACA GGGAAAGAAAGCAAGG while its reverse primer was CAGATGGGGAAGAGGTGA. All experiments were done in duplicates. The Human Protein Atlas (HPA) database (https://www.proteinatlas.org/) was used to evaluate the protein expression levels of the five glycolysis-related genes in LIHC tissues, COAD tissues and corresponding normal tissues (Additional file 1: Appendix S1).

\section{Statistical analysis}

We used the median value of the risk score to assign the 296 patients into high- and low-risk groups. KaplanMeier curves and log-rank methods were used to assess the prognostic significance of the risk score. Next, differential expression of the selected genes was examined and classified into high- and low-risk groups according to the median risk score. The receiver operating characteristic (ROC) curve analysis was performed to assess the sensitivity and specificity of prognostic prediction while the univariate and multivariate Cox analyses were performed to determine whether the risk score was an independent indicator of other clinical characteristics, including age, gender, grade and stage. Hazard ratios (HRs) and 95\% 
Table 1 Clinical pathological parameters of Asian patients with gastrointestinal cancer in this research

\begin{tabular}{|c|c|c|c|}
\hline Tumor type & Clinical characteristic & & $\mathrm{N}(\%)$ \\
\hline \multirow[t]{8}{*}{ Liver hepatocellular carcinoma (LIHC) } & Age (years) & $>65$ & $36(22.78)$ \\
\hline & & $\leq 65$ & $122(77.22)$ \\
\hline & Gender & Male & $124(78.48)$ \\
\hline & & Female & $34(21.52)$ \\
\hline & Stage & |-I| stage & $151(95.57)$ \\
\hline & & III-IV stage & $7(4.43)$ \\
\hline & Vital status & Alive & $114(72.15)$ \\
\hline & & Dead & $44(27.85)$ \\
\hline \multirow[t]{10}{*}{ Stomach adenocarcinoma (STAD) } & Age (years) & $>65$ & $41(55.41)$ \\
\hline & & $\leq 65$ & $33(44.59)$ \\
\hline & Gender & Male & $49(66.22)$ \\
\hline & & Female & $25(33.78)$ \\
\hline & Stage & |- || stage & $43(58.11)$ \\
\hline & & III-IV stage & $29(39.19)$ \\
\hline & & Not reported & $2(2.70)$ \\
\hline & Vital status & Alive & $54(72.97)$ \\
\hline & & Dead & $19(25.68)$ \\
\hline & & Not reported & $1(1.35)$ \\
\hline \multirow[t]{9}{*}{ Esophageal carcinoma (ESCA) } & Age (years) & $>65$ & $6(15.79)$ \\
\hline & & $\leq 65$ & $32(84.21)$ \\
\hline & Gender & Male & $35(92.11)$ \\
\hline & & Female & $3(7.89)$ \\
\hline & Stage & |-Il stage & $11(28.95)$ \\
\hline & & III-IV stage & $6(15.79)$ \\
\hline & & Not reported & $21(55.26)$ \\
\hline & Vital status & Alive & $31(81.58)$ \\
\hline & & Dead & $7(18.42)$ \\
\hline \multirow[t]{8}{*}{ Pancreatic adenocarcinoma (PAAD) } & Age (years) & $>65$ & $4(36.36)$ \\
\hline & & $\leq 65$ & $7(63.64)$ \\
\hline & Gender & Male & $5(45.45)$ \\
\hline & & Female & $6(54.55)$ \\
\hline & Stage & |-Il stage & $11(100.00)$ \\
\hline & & III-IV stage & $0(0.00)$ \\
\hline & Vital status & Alive & $6(54.55)$ \\
\hline & & Dead & $5(45.45)$ \\
\hline \multirow[t]{8}{*}{ Colon adenocarcinoma (COAD) } & Age (years) & $>65$ & $2(18.18)$ \\
\hline & & $\leq 65$ & $9(81.82)$ \\
\hline & Gender & Male & $8(72.73)$ \\
\hline & & Female & $3(27.27)$ \\
\hline & Stage & I-II stage & $10(90.91)$ \\
\hline & & III-IV stage & $1(9.09)$ \\
\hline & Vital status & Alive & $9(81.82)$ \\
\hline & & Dead & $2(18.18)$ \\
\hline \multirow[t]{6}{*}{ Cholangiocarcinoma (CHOL) } & Age (years) & $>65$ & $2(66.67)$ \\
\hline & & $\leq 65$ & $1(33.33)$ \\
\hline & Gender & Male & $2(66.67)$ \\
\hline & & Female & $1(33.33)$ \\
\hline & Stage & |-II stage & $3(100.00)$ \\
\hline & & III-IV stage & $0(0.00)$ \\
\hline
\end{tabular}


Table 1 (continued)

\begin{tabular}{|c|c|c|c|}
\hline Tumor type & Clinical characteristic & & $\mathrm{N}(\%)$ \\
\hline & Vital status & Alive & $1(33.33)$ \\
\hline & & Dead & $2(66.67)$ \\
\hline \multirow[t]{8}{*}{ Rectum adenocarcinoma (READ) } & Age (years) & $>65$ & $0(0.00)$ \\
\hline & & $\leq 65$ & $1(100.00)$ \\
\hline & Gender & Male & $1(100.00)$ \\
\hline & & Female & $0(0.00)$ \\
\hline & Stage & |-II stage & $1(100.00)$ \\
\hline & & III-IV stage & $0(0.00)$ \\
\hline & Vital status & Alive & $1(100.00)$ \\
\hline & & Dead & $0(0.00)$ \\
\hline
\end{tabular}

confidence intervals (CIs) were used to assess the relative risk. Moreover, survival curves of clinic-pathologic characteristics and model validation between the two groups were created using the Kaplan-Meier method. $p \leq 0.05$ was considered statistically significant. All statistical analyses were performed using the R 3.6.3 and GraphPad Prism 7 softwares.

\section{Results \\ Differently expressed glycolysis-related genes in Asian gastrointestinal cancer patients}

We obtained the mRNA expression profiles and clinical data for 296 Asian GI cancer patients from the TCGA database. Compared to normal tissues, GSEA revealed that glycolysis-related gene sets were significantly enriched in Asian GI tumor tissues (Fig. 1a-e). Using $\mid \log 2$ (Fold Change) $\mid>0$ and $p<0.05$, we finally identified 19 up-regulated and 138 down-regulated glycolysisrelated genes in Asian GI tumor and non-tumor tissues (Fig. 1f). Heat maps were established to show the differentially expressed genes between the tumor and normal groups (Fig. 1g).

\section{Construction of a risk score formula as an indicator of prognosis with the univariate Cox regression analysis} We used the univariate Cox regression analysis to screen and identify the genes associated with prognosis and survival. Ten mRNAs (RBCK1, HS2ST1, GPD1, SRD5A3, HAX1, GNPDA1, CDK1, NUP62, HDLBP and STMN1) were screened and identified as independent potential factors associated with poor prognosis. The candidate mRNAs were classified into two types: a risk type (RBCK1, HS2ST1, SRD5A3, HAX1, GNPDA1, HDLBP and STMN1) with $\mathrm{HR}>1$, which was associated with poor prognosis and a protective type (GPD1, CDK1, NUP62,) with $\mathrm{HR}<1$, which was associated with good prognosis (data not shown). Pearson correlation coefficients for the 10 mRNAs revealed strong correlations between: CDK1 and NUP62; STMN1 and
NUP62; GNPDA1 and NUP62; HS2ST1 and NUP62; GPD1 and NUP62; STMN1 and CDK1; GNPDA1 and CDK1; HS2ST1 and CDK1; GNPDA1 and STMN1; HS2ST1 and GNPDA1; RBCK1 and GNPDA1 as well as between HDLBP and HS2ST1, with a correlation coefficient greater than 0.3 (Fig. 2a). Using the expression levels of the 10 mRNAs together with their regression coefficients as assessed by multivariate Cox analysis, a prognostic risk score formula was established: Risk score $=0.3459 \times$ expression of RBCK1 $10.5377 \times$ expression of HS2ST1 $-0.3413 \times$ expression of GPD1 $+0.3543 \times$ expression of SRD5A3+0.6679 $\times$ expression of HAX1 $+0.4753 \times$ expression of GNPDA1 $0.3001 \times$ expression of CDK1-0.6322 $\times$ expression of NUP62 $+0.5384 \times$ expression of HDLBP $+0.3651 \times$ expression of STMN1. ROC curve analysis of the mRNA signature was 0.744 at 5 years, indicating a good performance in predicting the prognosis of GI cancers (Fig. 2b). Subsequently, patients were assigned into low- and high-risk groups based on the median value of risk scores (Fig. 2c). We evaluated the survival times of patients in the high- and low-risk groups and found that mortality rates for patients with high-risk scores were higher than those with low-risk scores (Fig. 2d). Heatmap analysis was performed to reveal the expression profiles of the $10 \mathrm{mRNAs}$. Based on the survival risk score of the 10-mRNA expression, patients were divided into a lowor high-risk groups using the median risk score (Fig. 2e).

\section{Construction of the five-gene signature as an indicator for prognosis}

LASSO COX regression analysis was performed to optimize the prognostic model and prevent overfitting (Fig. 3a). It was found that the regression coefficient for each gene and the model achieved the best performance (Fig. 3b). Finally, five genes were screened as independent potential prognostic factors for OS. NUP85, HAX1, GNPDA1 and HDLBP with $\mathrm{HR}>1$ were considered as risk genes, whereas GPD1 with $\mathrm{HR}<1$ was considered as a protective gene (Fig. 3c and 


\section{(See figure on next page.)}

Fig. 1 Performance of GSEA and differential expression analysis of glycolysis-related genes based on the Asian GI cancer patients of TCGA datasets. Enrichment analysis was performed on the selected gene sets, including BIOCARTA_GLYCOLYSIS_PATHWAY (a), GO_GLYCOLYTIC_PROCESS (b), HALLMARK_GLYCOLYSIS (c), KEGG_GLYCOLYSIS_GLUCONEOGENESIS (d) and REACTOME_GLYCOLYSIS (e). Volcano map (f) and heatmap (g) of glycolytic genes expressed differentially in tumor and normal tissues

Table 2). Similarly, we calculated the Pearson correlation coefficients for the five mRNAs and found strong correlations between GNPDA1 and NUP85, with a correlation coefficient greater than 0.3 (Fig. 4a). Moreover, we established a prognostic risk score formula as previously described: Risk score $=0.4761 \times$ expression of NUP85-0.1974 $\times$ expression of GPD1 $+0.7262 \times$ expression of HAX1 $+0.4541 \times$ expression of GNPDA1 $+0.5417 \times$ expression of HDLBP. The ROC curve analysis with a five-mRNA signature was 0.757 at 5 years, better than 0.744 of the previous model, indicating that this model has a high sensitivity and specificity in predicting survival outcomes in Asian GI cancer patients (Fig. 4b). Based on the median value of the risk score, patients were assigned into low- and high-risk groups (Fig. 4c). Analysis of survival outcomes of patients in the high- and low-risk groups showed that mortality rates for patients in the high-risk group were higher than those in the low-risk group (Fig. 4d). Then, heatmap analysis was performed to reveal the expression profiles of the five genes in the low- or high-risk group (Fig. 4e).

\section{Relationships between risk scores and clinical characteristics}

We performed the univariate and multivariate Cox regression analyses to evaluate the effects of risk scores and other clinical parameters, including age, gender, grade and stage, on the prognostic value. The univariate Cox regression analysis showed that the five-gene risk score $(\mathrm{HR}=1.537,95 \%$ CI 1.359-1.738, $p<0.001)$ and stage $(\mathrm{HR}=2.069,95 \%$ CI $1.529-2.798, p<0.001)$ correlated with the prognosis of GI cancer patients (Fig. 5a). In addition, the risk score and stage were found to be independent prognostic indicators $(p<0.001$, Fig. $5 b)$. These findings imply that the model can efficiently predict the prognosis of GI cancer with glycolysis-related gene risk score as an independent indicator (Fig. 5a, b). Furthermore, the expression levels of four mRNAs (NUP85, HAX1, GNPDA1 and HDLBP) were found to be elevated while that of GPD1 in tumors from the TCGA database was suppressed (Fig. 5c), consistent with our previous results. Then, we calculated the fivegene-based risk score for GI cancer patients. Patients in the high-risk group showed significantly poor OS than those in the low-risk group $(p<0.001)$ (Fig. $5 \mathrm{~d})$. To validate the generated prognostic model, GSE116174 and GSE84433 datasets were downloaded from Gene Expression Omnibus (GEO) and utilized as external samples. It was revealed that the survival and prognosis of Asian liver cancer patients and gastric cancer patients in the high-risk group were worse (Fig. 5e, f). Previous univariate and multivariate Cox regression analyses showed that tumor stage was correlated with the prognosis of GI cancer patients. Next, the Kaplan-Meier curve analysis was used to analyze colon cancer microarrays of Asian populations. We found that patients in stage III + IV $(p<0.001)$ and in T3-4 $(p<0.001)$ had poorer prognostic outcomes, consistent with our previous results (Fig. 6a). This model showed a good performance in stratifying age $\leq 65(p<0.001)$ and $>65(p=0.010)$, male $(p<0.001)$ and female $(p=0.004)$, grade G1-2 $(p<0.001)$ and G3-4 $(p=0.017)$, clinical-stage I-II $(p<0.001)$ and III-IV $(p=0.032)$, T1-2 $(p<0.001)$ and T3-4 $(p=0.021)$, M0 $(p<0.001)$ and N0 $(p<0.001)$ (Fig. 6). Analogous to the aforementioned results, the high-risk group in both subgroups was associated with worse OS, especially in patients without lymph node and/or distant metastasis. Overall, these results confirmed that the five-gene expression signature was an independent risk factor for predicting the survival of GI cancer patients in the Asian population.

\section{Expression levels of glycolysis-related genes in clinical tissue samples}

The HPA database was used to evaluate protein expression levels for NUP85, GPD1, HAX1, GNPDA1 and HDLBP in LIHC and COAD tissues compared to their expression in normal tissues. The NUP85, HAX1, GNPDA1 and HDLBP protein levels were significantly elevated in tumor tissues compared to normal samples, while GPD1 was significantly down-regulated in tumor tissues (Fig. 7a). In addition, NUP85, HAX1, GNPDA1 and HDLBP exhibited elevated mRNA expression levels in GI tumor tissues when compared to the adjacent nontumor tissues, whereas GPD1 expression was suppressed in GI tumor tissues compared to the non-tumor tissues (Fig. 7b). 
a

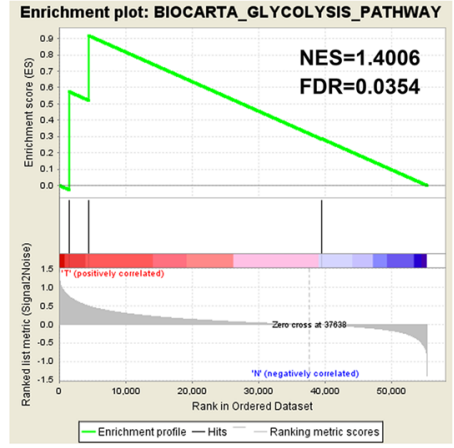

d

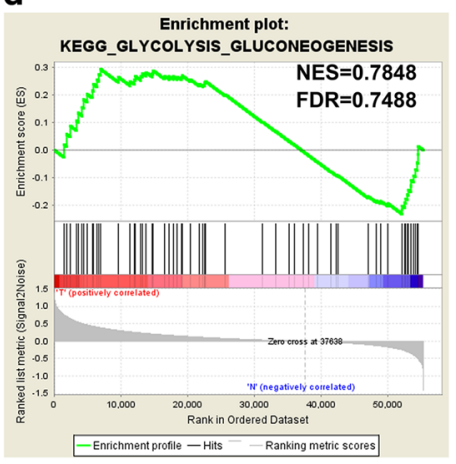

b

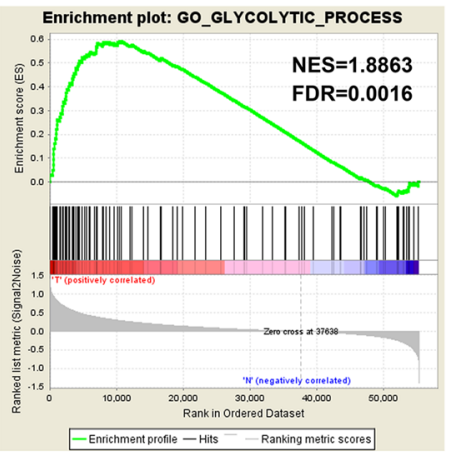

e

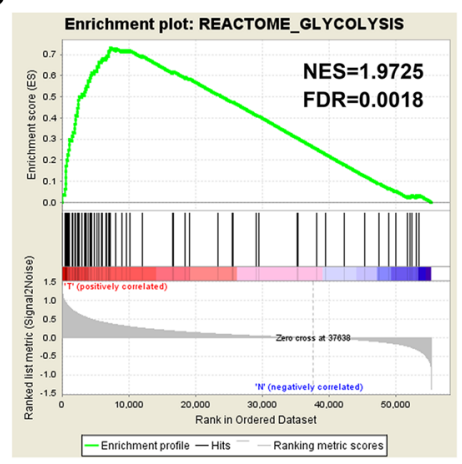

C

Enrichment plot: HALLMARK_GLYCOLYSIS

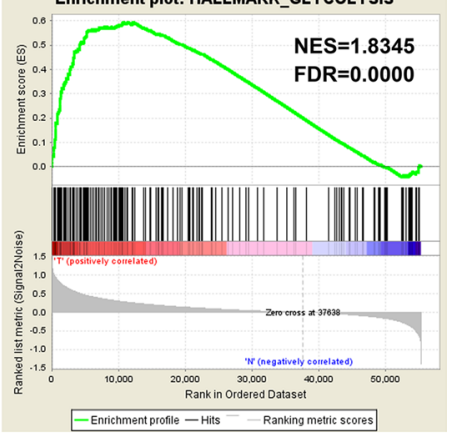

f

Volcano

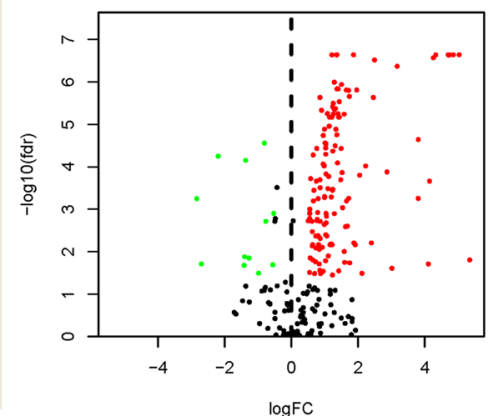

g

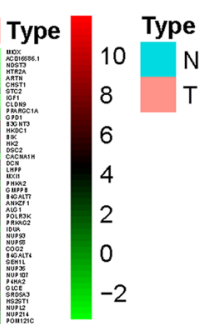




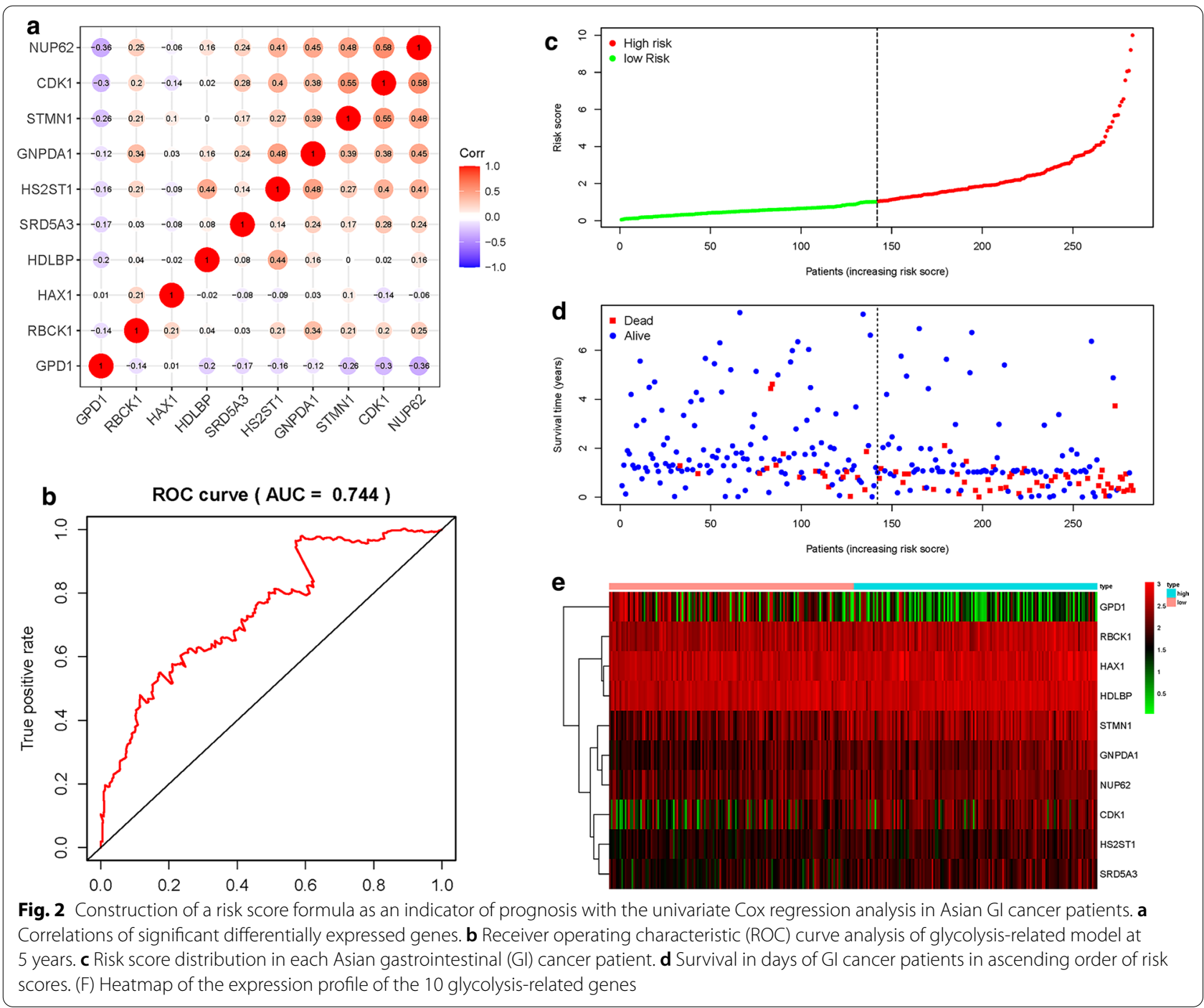

\section{Discussion}

A GI tumor is a type of tumor that occurs in complex digestive organs and whose biodiversity as well as tumor characteristics are inconsistent [37]. It mainly includes liver hepatocellular carcinoma (HCC), stomach adenocarcinoma, esophageal carcinoma, pancreatic adenocarcinoma, colon adenocarcinoma, cholangiocarcinoma and rectal adenocarcinoma. The prevalence of HCC is higher in Asia than in America and Europe. About $78 \%$ of the global HCC cases are reported in Asian countries, with China accounting for about $55 \%$ of the global HCC cases [38]. GI cancers are the most common malignancies in Asia, especially in China and Japan [1]. Due to its importance and superior therapeutic efficacies, gene therapy is widely being evaluated [39]. Identifying effective biomarkers to construct a prognostic model is of great clinical significance in informing the clinical decision-making process. Several predictive models for patient survival rates have been identified, however, they all have limitations. For example, in the autophagy-related gene prognosis prediction model, autophagy is a double-edged sword in various tumors, promoting as well as inhibiting cancer progression [40]. Therefore, the expression levels of autophagy related genes are unreliable. Similarly, in the immune response-related gene prognostic model, the established tumors often induce immune tolerance at an early stage of tumorigenesis, resulting in abnormal immune responses [41]. Glycolysis is the main energy source for cancer cells and the primary energy source for tumor invasion [42]. Studies have reported that glycolysis is a potential therapeutic and prognostic target for cancers [43-48]. Considering its role in cancer, constructing a glycolysis associated gene risk signature may be advantageous for the accurate diagnosis, therapy and prognosis of GI cancers. In addition, the prognostic 

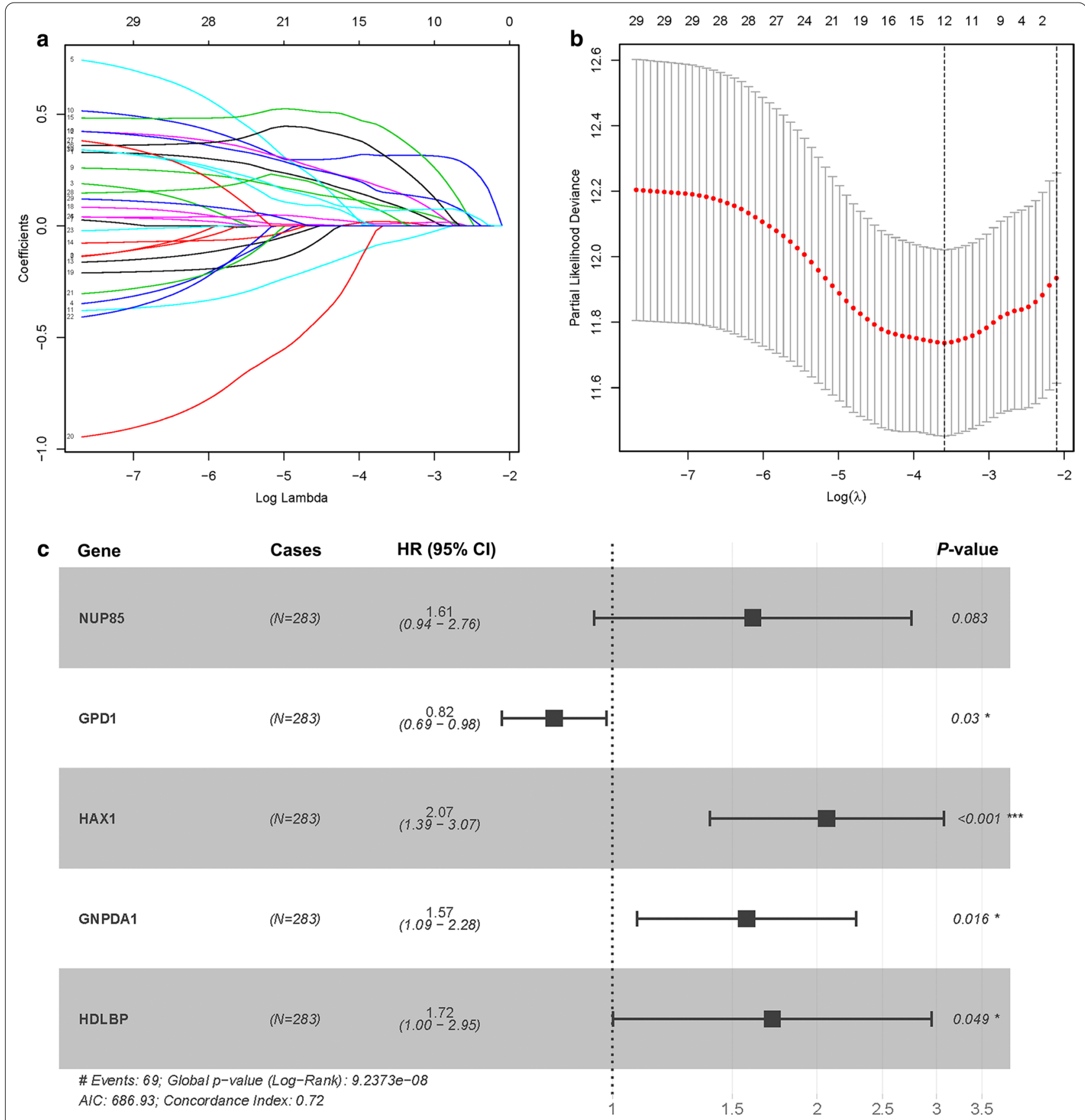

Fig. 3 LASSO Cox regression model construction. a Curves represent regularization paths of LASSO coefficients. b Partial likelihood deviance as a function of regularization parameter $\lambda$ in the TCGA dataset. $\mathbf{c}$ Forest plot describing the relationship between the five glycolysis-related gene expression and prognosis in $\mathrm{Gl}$ cancer, ${ }^{*} p<0.05$ and ${ }^{* * *} p<0.001$

significance of glycolysis-related genes in Asian GI cancers has not been reported.

We identified five novel glycolysis-associated genes (NUP85, GPD1, HAX1, GNPDA1, and HDLBP) in GI tumor and normal tissues. GPD1 was fond to be a positive prognostic gene, while NUP85, HAX1, GNPDA1,
HDLBP were negative prognostic genes. The nuclear pore complex (NPC) is a combination of macromolecules that cross the nuclear membrane to form a selective barrier between the nucleus and the cytoplasm [49]. The central channel of NPCs is filled with nucleoporins (NUPs), which can build a size-selective diffusion 
Table 2 The information of five prognostic mRNAs weighted by its multivariable LASSO regression coefficient, which importantly associated with overall survival in Asian patients with gastrointestinal cancer

\begin{tabular}{|c|c|c|c|c|c|}
\hline mRNA & Ensemble ID & Location & Risk coefficient & $\mathrm{HR}(95 \% \mathrm{Cl})$ & $P$ value \\
\hline NUP85 & ENSG00000125450 & Chromosome 17: 75,205,557-75,235,758 & 0.4761 & $1.6097(0.9400-2.7565)$ & 0.0828 \\
\hline GPD1 & ENSG00000167588 & Chromosome 12: 50,103,982-50,111,313 & -0.1974 & $0.8208(0.6871-0.9805)$ & 0.0295 \\
\hline HAX1 & ENSG00000143575 & Chromosome 1: 154,272,589-154,275,875 & 0.7262 & $2.0672(1.3904-3.0734)$ & 0.0003 \\
\hline GNPDA1 & ENSG00000113552 & Chromosome 5: 141,991,749-142,013,041 & 0.4541 & $1.5748(1.0864-2.2826)$ & 0.0165 \\
\hline HDLBP & ENSG00000115677 & Chromosome 2: 241,227,264-241,317,061 & 0.5417 & $1.7189(1.0023-2.9479)$ & 0.0490 \\
\hline
\end{tabular}

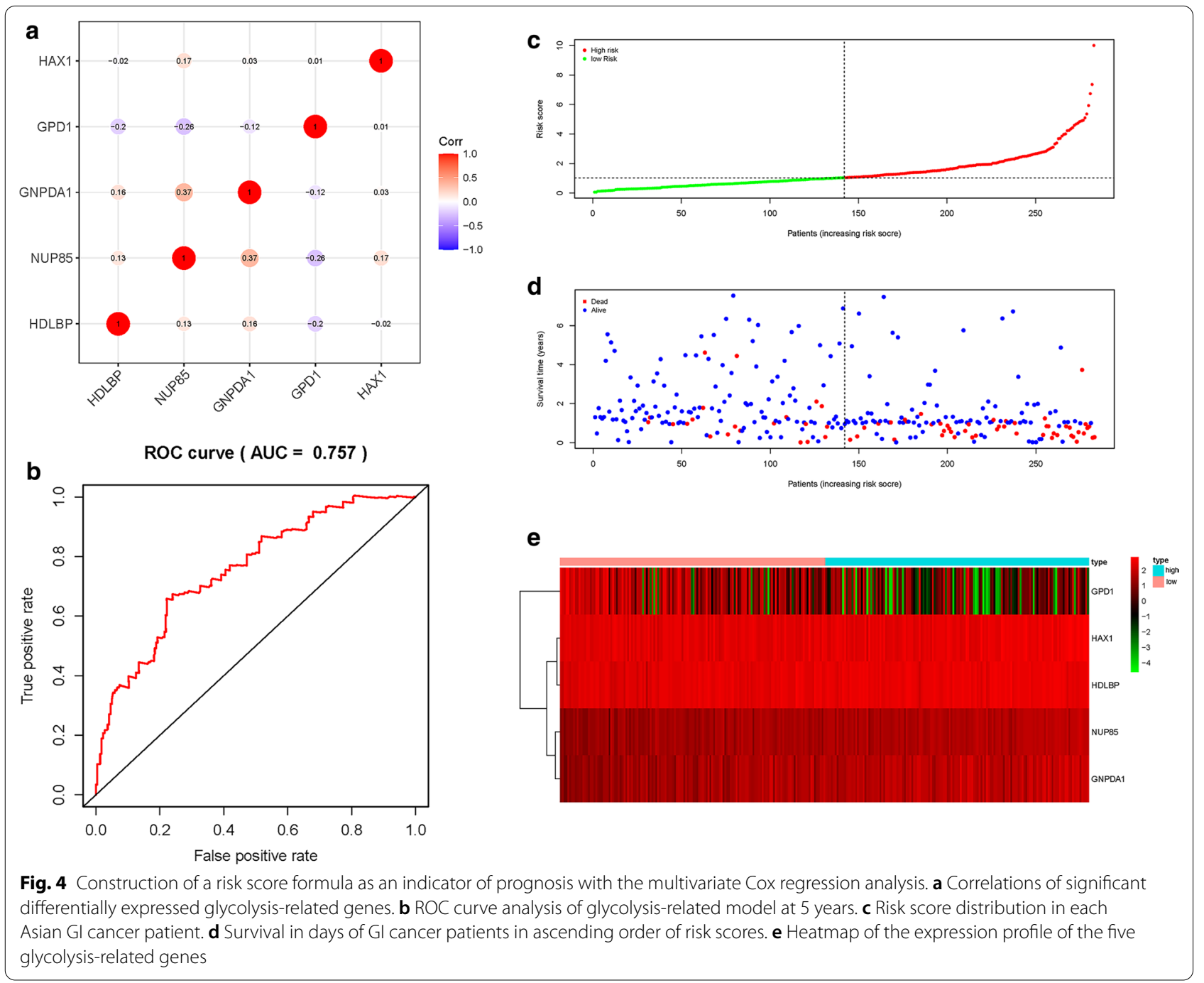

barrier for macromolecules larger than $40 \mathrm{kDa}$, while providing binding sites for nuclear transport receptors (nuclear transporters, importins and exportins), thereby transporting signal-carrying cargo across the NPC. NUP85 is an important member of the NPC outer ring [50]. It is postulated that dysregulated NUP85 functions may lead to tissue homeostasis imbalance. We found elevated NUP85 expression levels in tumors from the TCGA database in the Asian population, suggesting its possible involvement in the development of Asian GI cancers. It has been reported that targeting NUP85 in pancreatic cancer cells inhibits their invasiveness and 


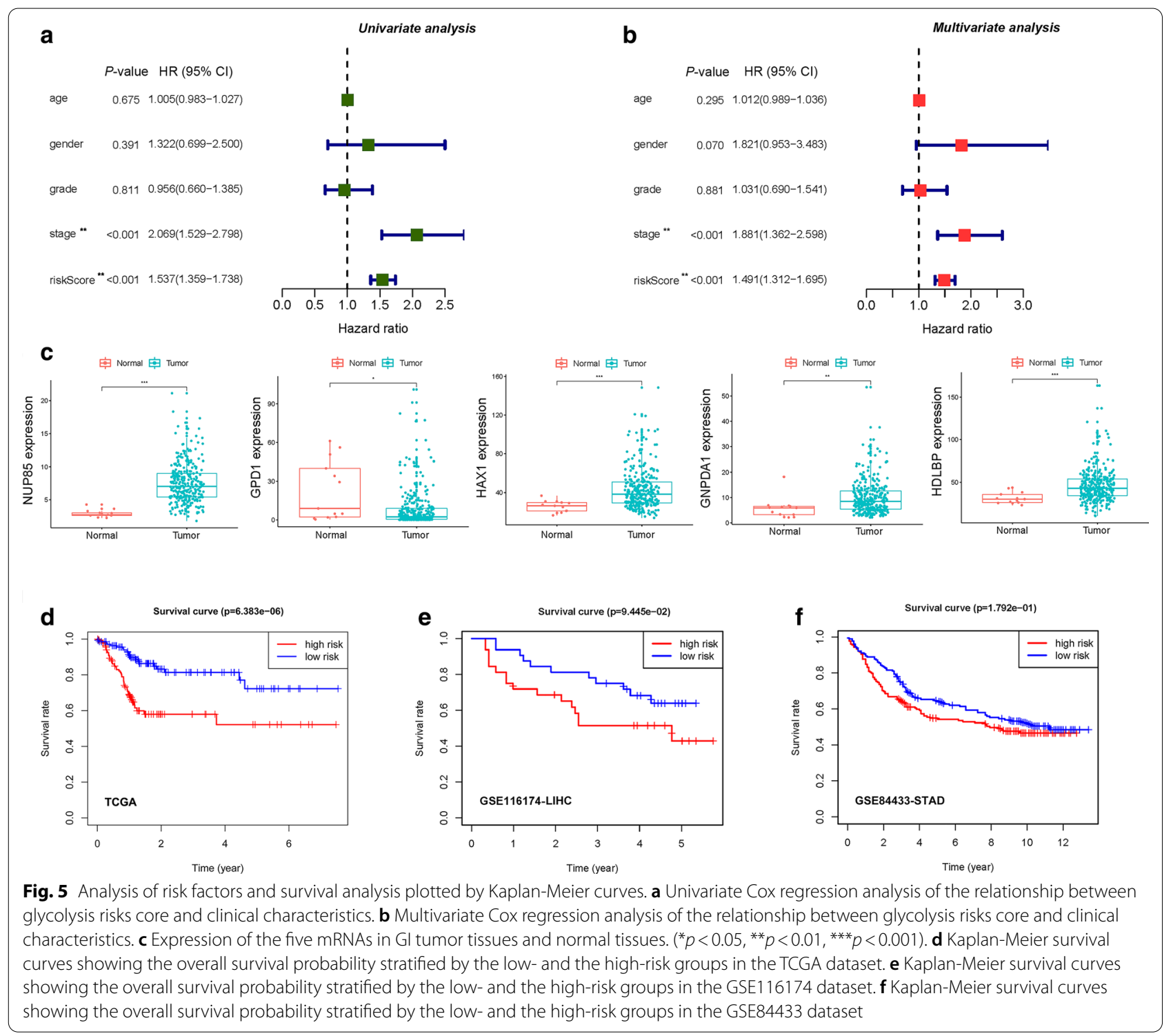

metastasis. Glycerol-3-phosphate dehydrogenase 1 (GPD1) is an NAD+/NADH dependent enzyme, which plays an important role in the cytoplasm as a glycerol phosphate shuttle [51]. Abnormal GDP1 expression may exert adverse effects on human health. GPD1 expression has been shown to be activated in early tumor development stages, such as those of glioblastoma [52]. However, GPD1 may exert an antitumor effect [53-55]. As a central component of lipid metabolism and synthesis, abnormal GDP1 activity can induce multiple digestive system diseases $[56,57]$. Therefore, the role of GPD1 in GI tumors is worthy of attention. We found that GDP1 expression levels in GI tumors was relatively low, which may be related to GPD1 deficiency and its effect on gluconeogenesis. In tumor sites, hematopoietic substrate-1-associated protein $\mathrm{X}-1$ (HAX-1) is highly expressed during neovascularization [58]. HAX-1 promotes the migration and invasion of carcinoma cells by disrupting apoptotic responses [58-60]. We also confirmed that elevated HAX-1 expression levels are closely correlated with tumor development. Glucosamine-6-phosphate isomerase 1 (GNPDA1) can catalyze the conversion of glucosamine 6-phosphate to fructose 6-phosphate and thereby increase the raw materials for glycolysis [61-63], which enhances cancer progression. GNPDA1 plays important roles in cell proliferation, migration and invasion $[64,65]$. Elevated GNPDA1 expression levels are associated with poor prognosis in patients with HCC, pancreatic cancer and colorectal cancer [64, 66-68]. Furthermore, highdensity lipoprotein binding protein (HDLBP), also known 

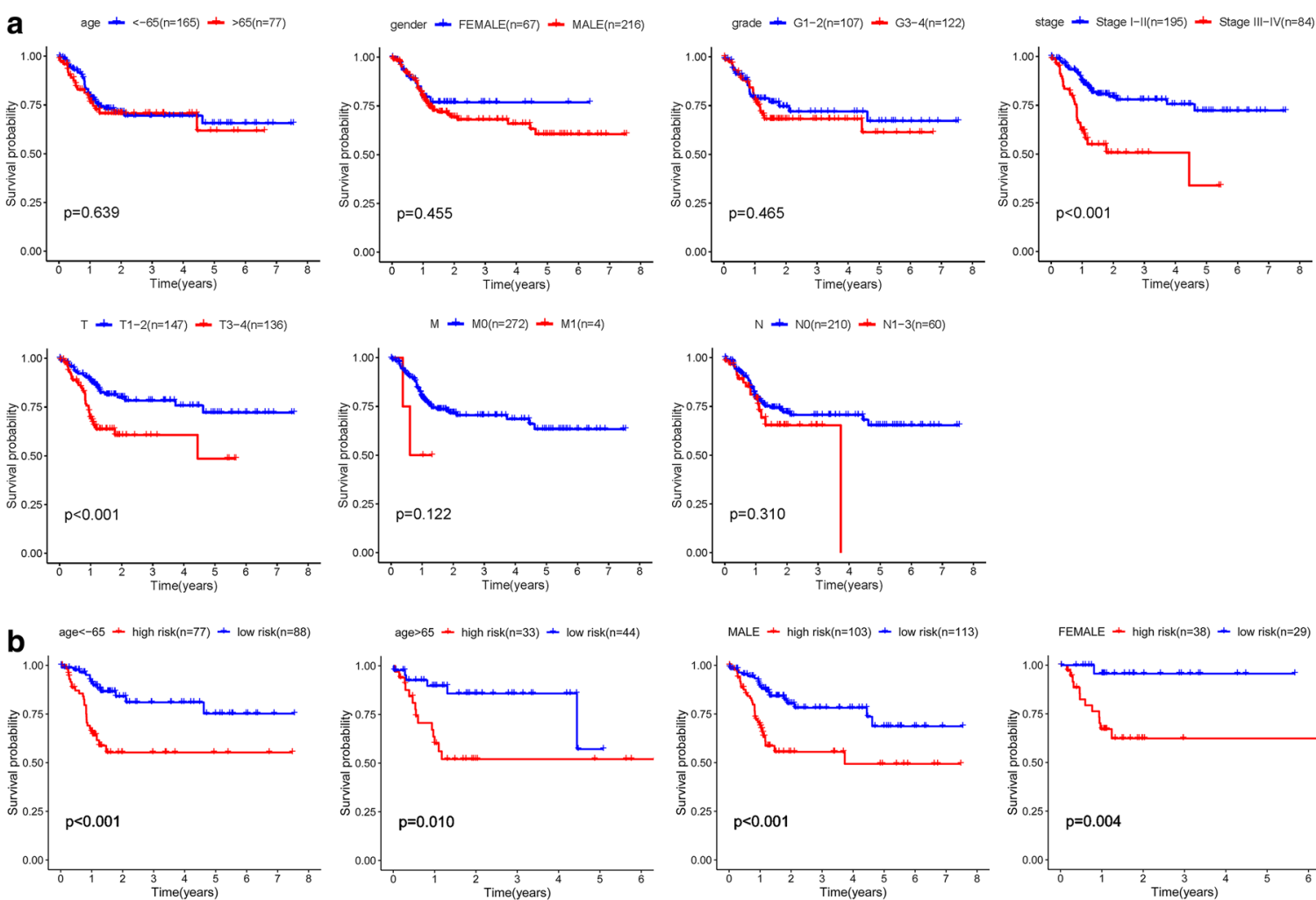

age $365+$ high risk(n=33) - low risk(n=44)
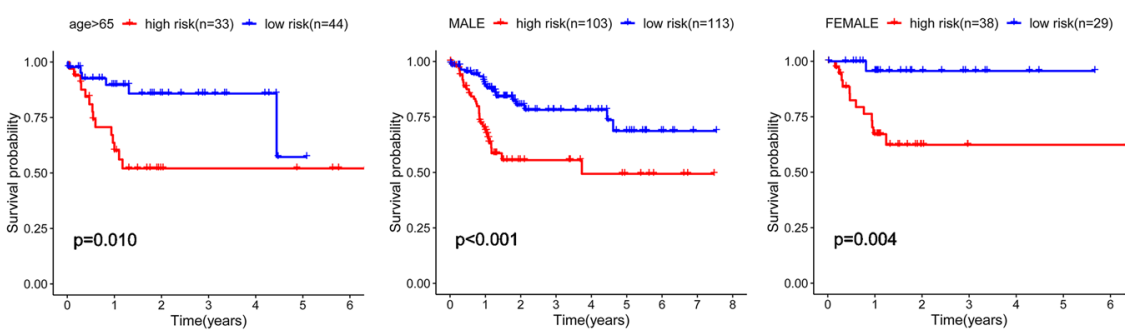

G1-2 - high risk(n=44) - low risk(n=63)

G3-4 - high risk(n=55) - low risk(n=67)
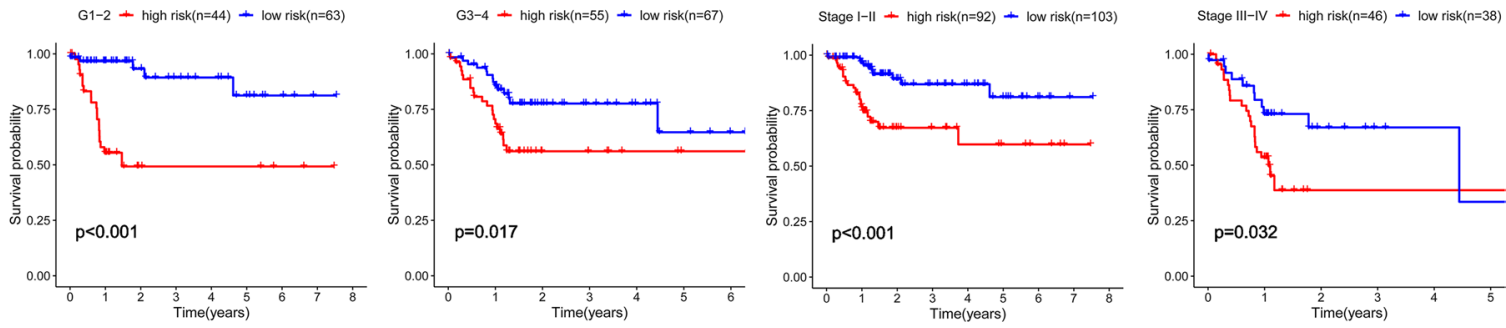

MO + high risk(n=135) + low risk(n=137)
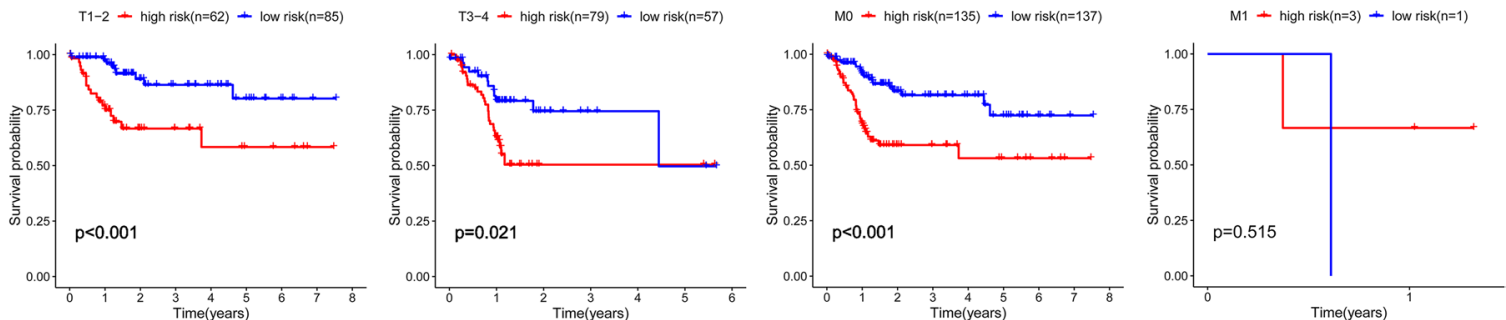

No + high risk(n=104) + low risk(n=106)

$\mathrm{N} 1-3-$ high risk(n=32) - low risk(n=28)
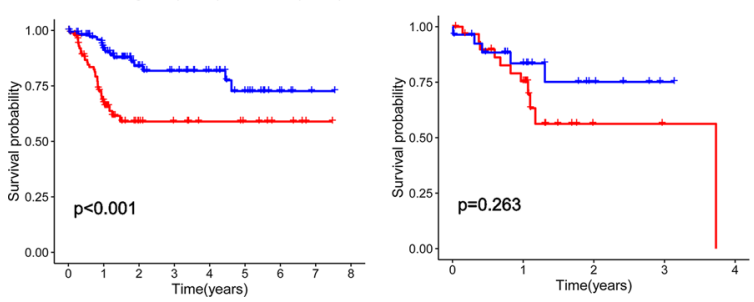

Fig. 6 Kaplan-Meier survival analysis for Asian Gl cancer patients in TCGA dataset. a Relationship between the clinical features and survival rate. b Prognosis of risk scores for the Asian Gl cancer patients categorized by the clinical feature 


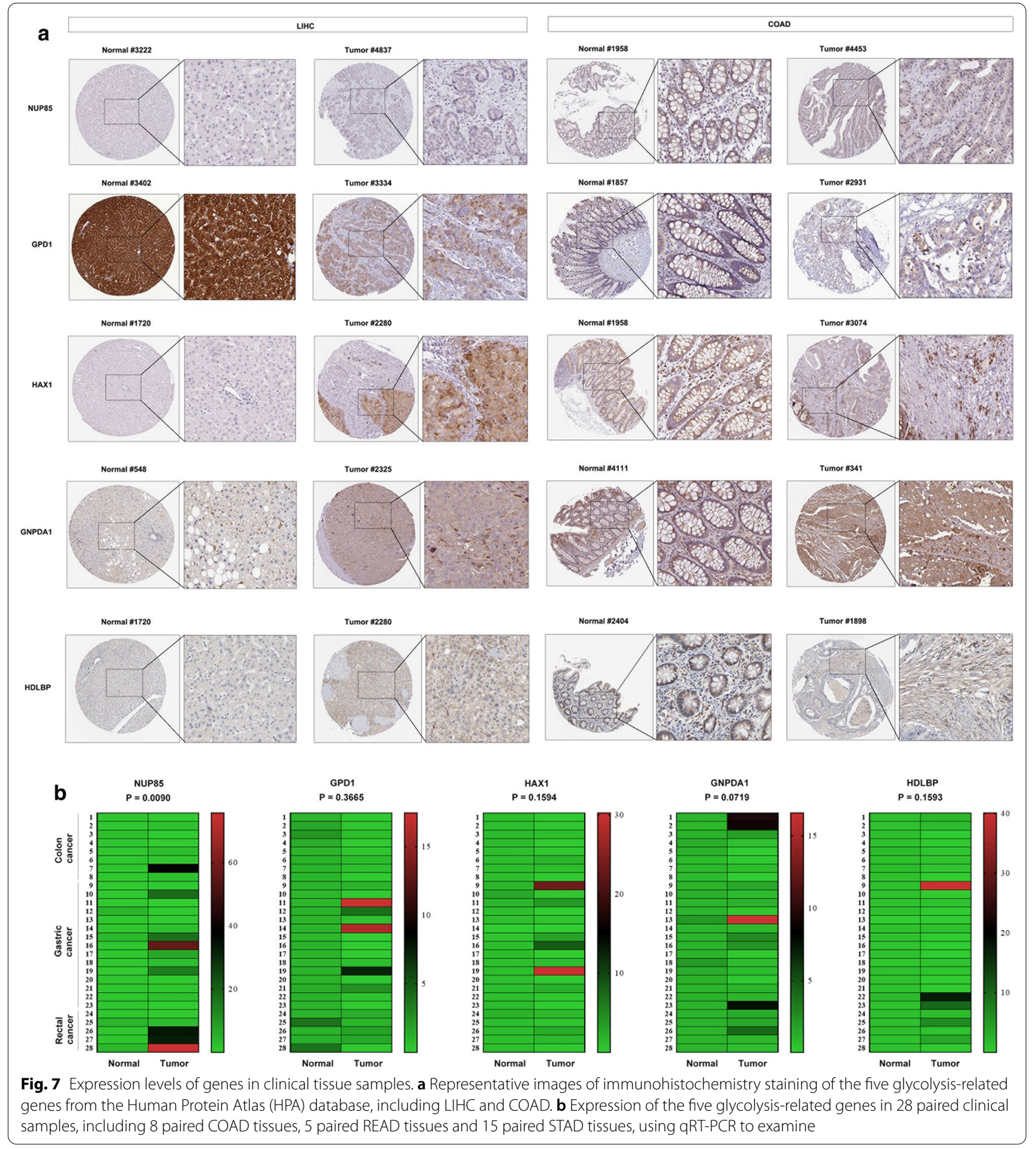

as vigilin, has been shown to play a significant role in cellular sterol metabolism in human atherogenesis [69]. Several studies have shown that vigilin is highly expressed in multiple cancers, including gastric cancer, suggesting it may be a promoter for carcinogenesis [70-72]. In conclusion, these five genes are involved in the progression of GI cancers and were used to establish a five-gene prognostic signature. GI cancer patients in the high-risk group exhibited significantly poor prognosis than those in the low-risk group. Due to the biological functions of the five genes in carcinogenesis and the significant correlation with the prognosis of GI cancer patients, the 


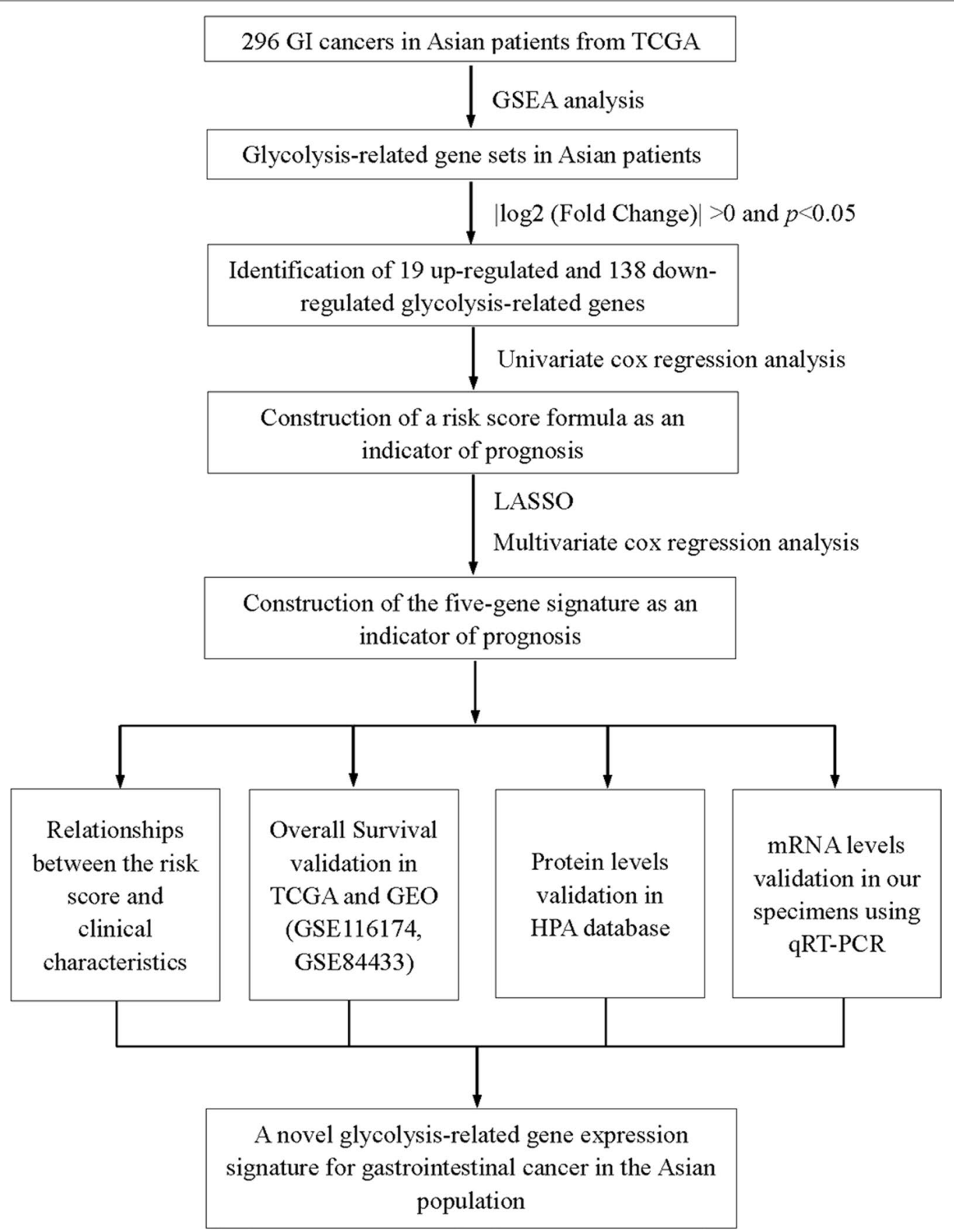

Fig. 8 A flowchart of the data analysis procedures

five-gene signature is a novel biomarker that can be used to inform clinical decisions (Fig. 8).

However, this study is associated with several limitations. Our datasets were mainly from the TCGA database in the Asian population. Although we validated the expression levels of the identified genes in the collected tissues, only a small number of Asian patient samples were represented. Further validation of the five-gene expression signature in a large sample population is necessary. Meanwhile, in Asian people of different ancestry, genetic variation should be considered as a correction factor. Besides, this study provides the possibility that the five-gene expression signature may function as a therapeutic and prognostic target, which 
was merely analyzed through available retrospective data. The underlying mechanisms of the five-gene expression signature in cancer progression should be elucidated through functional experiments. In recent years, studies have reported that non-coding RNA plays an important role in the initiation and progression of cancer. Aberrant expression of non-coding RNAs have been found to be involved in the regulation glycolysis associated genes [73-77]. Thus, further studies on the non-coding RNAs that are associated with glycolysis in GI cancer are also necessary. In summary, we identified and validated a glycolysis associated five-gene risk signature (NUP85, GPD1, HAX1, GNPDA1 and HDLBP) that can predict the OS of GI Asian cancer patients. This five-gene signature can be used as a novel tool in clinical practice. More studies should evaluate the roles of these genes in Asian GI cancers, which can provide the theoretical basis for clinical practice. Furthermore, more data is be needed to validate the general applicability of this signature in clinical decisions.

\section{Conclusions}

We systematically established five glycolysis-related genes (NUP85, GPD1, HAX1, GNPDA1 and HDLBP) in Asian GI cancers. Moreover, we established a fivegene expression signature and showed that the predictive model can independently predict the OS of Asian GI cancer patients by combining molecular signatures and clinical characteristics.

\section{Supplementary Information}

The online version contains supplementary material available at https://doi. org/10.1186/s12935-021-01857-4.

Additional file 1: Appendix S1. Basic information about the tumor samples we used in this study.

\begin{abstract}
Abbreviations
Gl cancer: Gastrointestinal cancer; TCGA: The Cancer Genome Atlas; LIHC: Liver hepatocellular carcinoma; STAD: Stomach adenocarcinoma; ESCA: Esophageal carcinoma; PAAD: Pancreatic adenocarcinoma; COAD: Colon adenocarcinoma; CHOL: Cholangiocarcinoma; READ: Rectum adenocarcinoma; GSEA: Gene Set Enrichment Analysis; ROC: Receiver operating characteristic; NUP85: Nucleoporin 8; HAX1: HCLS1 associated protein X-1; GNPDA1: Glucosamine6-phosphate deaminase 1; HDLBP: High density lipoprotein binding protein; GPD1: Glycerol-3-phosphate dehydrogenase 1; LASSO: Logistic least absolute shrinkage and selection operator; OS: Overall survival; MSigDB: Molecular signature database; FDR: False discovery rate; HR: Hazard ratio; qRT-PCR: Quantitative real-time PCR; RNA-seq: RNA sequencing.
\end{abstract}

\section{Acknowledgements}

Most of the data in this study were obtained through the Cancer Genome Atlas Database (TCGA), Gene Expression Omnibus (GEO), and Human Protein Atlas. We are grateful for the source of data used in our research.

\section{Authors' contributions}

CW, JY and YZ conceived and designed the model. RX, HT and JS analyzed the data and wrote the manuscript. SX, YL, YZ, XG, YM, DZ and CT contributed significantly to the data analyses and experiment, SW provided important suggestions. All authors read and approved the final manuscript.

\section{Funding}

This work was supported by the National Natural Science Foundation of China (81903353), the Technology Development Fund of Nanjing Medical University [NMUB2018001] and the project funded by the Priority Academic Program Development of Jiangsu Higher Education Institutions and the Collegiate Natural Science Foundation of Jiangsu Province [19KJB330003], and the Scientific Research Funding of Tongling Municipal Health Commission (201912).

\section{Availability of data and materials}

The data sets used and/or analyzed during the current study are publicly available data from The Cancer Genome Atlas (TCGA), Gene Expression Omnibus (GEO), and Human Protein Atlas. The figures and materials supporting the conclusions of this article are included within the article.

\section{Declarations}

\section{Ethics approval and consent to participate}

This research was approved by the Institutional Review Board of Nanjing Medical University and the Ethical committee of the Tongling People's Hospital (ethical review No.2019-008). Informed consent was obtained from all subjects.

\section{Consent for publication}

None.

\section{Competing interests}

The authors declare no competing financial interests.

\section{Author details}

${ }^{1}$ Key Lab of Modern Toxicology of Ministry of Education, Center for Global Health, School of Public Health, Nanjing Medical University, 101 Longmian Avenue, Nanjing 211166, People's Republic of China. ${ }^{2}$ State Key Lab of Reproductive Medicine, Institute of Toxicology, Nanjing Medical University, 101 Longmian Avenue, Nanjing 211166, People's Republic of China. ${ }^{3}$ Department of General Surgery, Tongling People's Hospital, 468 Bijiashan Road, Tongling, Anhui Province 244000, People's Republic of China. ${ }^{4}$ The First Clinical Medical College of Nanjing Medical University, Nanjing 211166, People's Republic of China. ${ }^{5}$ Department of Colorectal Surgery, the First Affiliated Hospital of Nanjing Medical University, Nanjing 210000, People's Republic of China. ${ }^{6}$ Department of Clinical Medicine and Rehabilitation, Jiangsu College of Nursing, 9 Keji Road, Huai'an 223005, People's Republic of China.

Received: 28 December 2020 Accepted: 24 February 2021 Published online: 04 March 2021

\section{References}

1. Bray F, Ferlay J, Soerjomataram I, Siegel RL, Torre LA, Jemal A. Global cancer statistics 2018: GLOBOCAN estimates of incidence and mortality worldwide for 36 cancers in 185 countries. CA Cancer J Clin. 2018;68(6):394-424.

2. Baj J, Brzozowska K, Forma A, Maani A, Sitarz E, Portincasa P. Immunological aspects of the tumor microenvironment and epithelial-mesenchymal transition in gastric carcinogenesis. Int J Mol Sci. 2020;21:7.

3. El-Zaatari M, Bishu S, Zhang M, Grasberger H, Hou G, Haley H, Humphries B, Syu LJ, Dlugosz AA, Luker K, et al. Aim2-mediated/IFN-beta-independent regulation of gastric metaplastic lesions via CD8+ T cells. JCI Insight. 2020;5:5.

4. Tian L, Lu Y, Yang T, Deng Z, Xu L, Yao W, Ma C, Li X, Zhang J, Liu Y, et al. aPKCiota promotes gallbladder cancer tumorigenesis and gemcitabine resistance by competing with Nrf2 for binding to Keap1. Redox Biol. 2019;22:101149. 
5. Du X, Zhang Z, Zheng X, Zhang H, Dong D, Zhang Z, Liu M, Zhou J. An electrochemical biosensor for the detection of epithelial-mesenchymal transition. Nat Commun. 2020;11(1):192.

6. Yuan Q, Miao J, Yang Q, Fang L, Fang Y, Ding H, Zhou Y, Jiang L, Dai C, Zen $\mathrm{K}$, et al. Role of pyruvate kinase M2-mediated metabolic reprogramming during podocyte differentiation. Cell Death Dis. 2020;1 1(5):355.

7. Nokin MJ, Durieux F, Peixoto P, Chiavarina B, Peulen O, Blomme A, Turtoi A, Costanza B, Smargiasso N, Baiwir D, et al. Methylglyoxal, a glycolysis side-product, induces Hsp90 glycation and YAP-mediated tumor growth and metastasis. Elife. 2016;5:8.

8. Wang Y, Lu JH, Wu QN, Jin Y, Wang DS, Chen YX, Liu J, Luo XJ, Meng Q, Pu HY, et al. LncRNA LINRIS stabilizes IGF2BP2 and promotes the aerobic glycolysis in colorectal cancer. Mol Cancer. 2019;18(1):174.

9. Zhang Z, Tan X, Luo J, Yao H, Si Z, Tong JS. The miR-30a-5p/CLCF1 axis regulates sorafenib resistance and aerobic glycolysis in hepatocellular carcinoma. Cell Death Dis. 2020;11(10):902

10. Yao X, He Z, Qin C, Deng X, Bai L, Li G, Shi J. SLC2A3 promotes macrophage infiltration by glycolysis reprogramming in gastric cancer. Cancer Cell Int. 2020;20:503.

11. Weng ML, Chen WK, Chen XY, Lu H, Sun ZR, Yu Q, Sun PF, Xu YJ, Zhu $M M$, Jiang $N$, et al. Fasting inhibits aerobic glycolysis and proliferation in colorectal cancer via the Fdft1-mediated AKT/mTOR/HIF1alpha pathway suppression. Nat Commun. 2020;11(1):1869.

12. Chen S, Cao G, Wu W, Lu Y, He X, Yang L, Chen K, Chen B, Xiong M. Mining novel cell glycolysis related gene markers that can predict the survival of colon adenocarcinoma patients. Biosci Rep. 2020;40:8.

13. Jiang J, Zheng Q, Zhu W, Chen X, Lu H, Chen D, Zhang H, Shao M, Zhou $\mathrm{L}$, Zheng $\mathrm{S}$. Alterations in glycolytic/cholesterogenic gene expression in hepatocellular carcinoma. Aging (Albany NY). 2020;12(11):10300-16.

14. Wang Y, Zhao W, Xiao Z, Guan G, Liu X, Zhuang M. A risk signature with four autophagy-related genes for predicting survival of glioblastoma multiforme. J Cell Mol Med. 2020;24(7):3807-21.

15. Wang K, Chen X, Jin C, Mo J, Jiang H, Yi B, Chen X. A novel immunerelated genes prognosis biomarker for hepatocellular carcinoma. Aging (Albany NY). 2020;12:8.

16. Carone C, Olivani A, Dalla Valle R, Manuguerra R, Silini EM, Trenti T, Missale G, Cariani E. Immune Gene Expression Profile in Hepatocellular Carcinoma and Surrounding Tissue Predicts Time to Tumor Recurrence. Liver Cancer. 2018;7(3):277-94.

17. Rademaker G, Costanza B, Bellier J, Herfs M, Peiffer R, Agirman F, Maloujahmoum N, Habraken Y, Delvenne P, Bellahcene A, et al. Human colon cancer cells highly express myoferlin to maintain a fit mitochondrial network and escape p53-driven apoptosis. Oncogenesis. 2019;8(3):21.

18. Guan Y, Cao Z, Du J, Liu T, Wang T. Circular RNA circPITX1 knockdown inhibits glycolysis to enhance radiosensitivity of glioma cells by miR329-3p/NEK2 axis. Cancer Cell Int. 2020;20:80

19. Menegon S, Columbano A, Giordano S. The Dual Roles of NRF2 in Cancer. Trends Mol Med. 2016;22(7):578-93.

20. Lau A, Villeneuve NF, Sun Z, Wong PK, Zhang DD. Dual roles of Nrf2 in cancer. Pharmacol Res. 2008;58(5-6):262-70.

21. Jeong WS, Jun M, Kong AN. Nrf2: a potential molecular target for cancer chemoprevention by natural compounds. Antioxid Redox Signal. 2006:8(1-2):99-106.

22. Hayes JD, MCMahon M, Chowdhry S, Dinkova-Kostova AT. Cancer chemoprevention mechanisms mediated through the Keap1-Nrf2 pathway. Antioxid Redox Sign. 2010;13(11):1713-48.

23. Magesh S, Chen Y, Hu LQ. Small molecule modulators of Keap1-Nrf2-ARE pathway as potential preventive and therapeutic agents. Med Res Rev. 2012;32(4):687-726.

24. Ren D, Villeneuve NF, Jiang T, Wu T, Lau A, Toppin HA, Zhang DD. Brusatol enhances the efficacy of chemotherapy by inhibiting the Nrf2-mediated defense mechanism. Proc Natl Acad Sci U S A. 2011;108(4):1433-8.

25. Jiang T, Chen N, Zhao F, Wang XJ, Kong B, Zheng W, Zhang DD. High levels of Nrf2 determine chemoresistance in type II endometrial cancer. Cancer Res. 2010;70(13):5486-96.

26. Wang XJ, Sun Z, Villeneuve NF, Zhang S, Zhao F, Li Y, Chen W, Yi X, Zheng W, Wondrak GT, et al. Nrf2 enhances resistance of cancer cells to chemotherapeutic drugs, the dark side of Nrf2. Carcinogenesis. 2008;29(6):1235-43

27. Shibata T, Kokubu A, Gotoh M, Ojima H, Ohta T, Yamamoto M, Hirohashi S. Genetic alteration of Keap1 confers constitutive Nrf2 activation and resistance to chemotherapy in gallbladder cancer. Gastroenterology. 2008;135(4):1358-68.

28. Purohit V, Wang L, Yang H, Li J, Ney GM, Gumkowski ER, Vaidya AJ, Wang A, Bhardwaj A, Zhao E, et al. ATDC binds to KEAP1 to drive NRF2-mediated tumorigenesis and chemoresistance in pancreatic cancer. Genes Dev. 2021;5:87.

29. Sousa CM, Kimmelman AC. The complex landscape of pancreatic cancer metabolism. Carcinogenesis. 2014;35(7):1441-50.

30. White E. Exploiting the bad eating habits of Ras-driven cancers. Genes Dev. 2013;27(19):2065-71.

31. Altman BJ, Stine ZE, Dang CV. From Krebs to clinic: glutamine metabolism to cancer therapy. Nat Rev Cancer. 2016;16(11):749.

32. Mukhopadhyay S, Goswami D, Adiseshaiah PP, Burgan W, Yi M, Guerin TM, Kozlov SV, Nissley DV, McCormick F. Undermining glutaminolysis bolsters chemotherapy while NRF2 promotes chemoresistance in KRAS-Driven pancreatic cancers. Cancer Res. 2020;80(8):1630-43.

33. Grabocka E, Bar-Sagi D. Mutant KRAS Enhances Tumor Cell Fitness by Upregulating Stress Granules. Cell. 2016;167(7):1803-13.

34. Tao S, Wang S, Moghaddam SJ, Ooi A, Chapman E, Wong PK, Zhang DD. Oncogenic KRAS confers chemoresistance by upregulating NRF2. Cancer Res. 2014;74(24):7430-41.

35. Poljsak B, Kovac V, Dahmane R, Levec T, Starc A. Cancer Etiology: A Metabolic Disease Originating from Life's Major Evolutionary Transition? Oxid Med Cell Longev. 2019;2019:7831952.

36. Wang C, Zhu J, Zhang Z, Chen H, Ji M, Chen C, Hu Y, Yu Y, Xia R, Shen J, et al. Rno-miR-224-5p contributes to 2,2',4,4'-tetrabromodiphenyl etherinduced low triiodothyronine in rats by targeting deiodinases. Chemosphere. 2020;246:125774.

37. Stratford JK, Bentrem DJ, Anderson JM, Fan C, Volmar KA, Marron JS, Routh ED, Caskey LS, Samuel JC, Der CJ, et al. A six-gene signature predicts survival of patients with localized pancreatic ductal adenocarcinoma. PLoS Med. 2010;7(7):e1000307.

38. Amarapurkar D, Han KH, Chan HL, Ueno Y, Asia-Pacific Working Party on Prevention of Hepatocellular C. Application of surveillance programs for hepatocellular carcinoma in the Asia-Pacific Region. J Gastroenterol Hepatol. 2009; 24(6):955-961.

39. Park HS, Kwon WS, Park S, Jo E, Lim SJ, Lee CK, Lee JB, Jung M, Kim $\mathrm{HS}$, Beom SH, et al. Comprehensive immune profiling and immunemonitoring using body fluid of patients with metastatic gastric cancer. J Immunother Cancer. 2019:7(1):268.

40. Wang Y, Xiong H, Liu D, Hill C, Ertay A, Li J, Zou Y, Miller P, White E, Downward J, et al. Autophagy inhibition specifically promotes epithelialmesenchymal transition and invasion in RAS-mutated cancer cells. Autophagy. 2019;15(5):886-99.

41. Mizuno R, Kawada K, Sakai Y. Prostaglandin E2/EP signaling in the tumor microenvironment of colorectal cancer. Int J Mol Sci. 2019:20:24.

42. Zheng YL, Li L, Jia YX, Zhang BZ, Li JC, Zhu YH, Li MQ, He JZ, Zeng TT, Ban $\mathrm{XJ}$, et al. LINC01554-mediated glucose metabolism reprogramming suppresses tumorigenicity in hepatocellular carcinoma via downregulating PKM2 expression and inhibiting Akt/mTOR signaling pathway. Theranostics. 2019;9(3):796-810.

43. Yu M, Chen S, Hong W, Gu Y, Huang B, Lin Y, Zhou Y, Jin H, Deng Y, Tu L, et al. Prognostic role of glycolysis for cancer outcome: evidence from 86 studies. J Cancer Res Clin Oncol. 2019;145(4):967-99.

44. Moreno-Felici J, Hyrossova P, Arago M, Rodriquez-Arevalo S, GarciaRoves PM, Escolano C, Perales JC. Phosphoenolpyruvate from glycolysis and PEPCK regulate cancer cell fate by altering cytosolic $\mathrm{Ca}(2)$. Cells. 2019;9:15.

45. Xi Y, Yuan P, LiT, Zhang M, Liu MF, Li B. hENT1 reverses chemoresistance by regulating glycolysis in pancreatic cancer. Cancer Lett. 2020;479:112-22.

46. Wei J, Huang K, Chen Z, Hu M, Bai Y, Lin S, Du H. Characterization of glycolysis-associated molecules in the tumor microenvironment revealed by pan-cancer tissues and lung cancer single cell data. Cancers (Basel). 2020;12:7.

47. Wang X, Zhang H, Yang H, Bai M, Ning T, Deng T, Liu R, Fan Q, Zhu K, Li J, et al. Exosome-delivered circRNA promotes glycolysis to induce chemoresistance through the miR-122-PKM2 axis in colorectal cancer. Mol Oncol. 2020;14(3):539-55.

48. Vasaikar S, Huang C, Wang X, Petyuk VA, Savage SR, Wen B, Dou Y, Zhang Y, Shi Z, Arshad OA, et al. Proteogenomic analysis of human colon cancer reveals new therapeutic opportunities. Cell. 2019;177(4):1035-49. 
49. Beck M, Hurt E. The nuclear pore complex: understanding its function through structural insight. Nat Rev Mol Cell Biol. 2017;18(2):73-89.

50. Braun DA, Lovric S, Schapiro D, Schneider R, Marquez J, Asif M, Hussain MS, Daga A, Widmeier E, Rao J, et al. Mutations in multiple components of the nuclear pore complex cause nephrotic syndrome. J Clin Invest. 2018;128(10):4313-28

51. Mracek T, Drahota Z, Houstek J. The function and the role of the mitochondrial glycerol-3-phosphate dehydrogenase in mammalian tissues. Biochim Biophys Acta. 2013;1827(3):401-10.

52. Rusu P, Shao C, Neuerburg A, Acikgoz AA, Wu Y, Zou P, Phapale P, Shankar TS, Doring K, Dettling S, et al. GPD1 specifically marks dormant glioma stem cells with a distinct metabolic profile. Cell Stem Cell. 2019;25(2):241-57.

53. Xie J, Ye J, Cai Z, Luo Y, Zhu X, Deng Y, Feng Y, Liang Y, Liu R, Han Z, et al. GPD1 enhances the anticancer effects of metformin by synergistically increasing total cellular glycerol-3-phosphate. Cancer Res. 2020;80(11):2150-62.

54. Yoneten KK, Kasap M, Akpinar G, Gunes A, Gurel B, Utkan NZ. Comparative Proteome Analysis of Breast Cancer Tissues Highlights the Importance of Glycerol-3-phosphate Dehydrogenase 1 and Monoacylglycerol Lipase in Breast Cancer Metabolism. Cancer Genomics Proteomics. 2019;16(5):377-97.

55. Zhou C, Yu J, Wang M, Yang J, Xiong H, Huang H, Wu D, Hu S, Wang $Y$, Chen XZ, et al. Identification of glycerol-3-phosphate dehydrogenase 1 as a tumour suppressor in human breast cancer. Oncotarget. 2017;8(60):101309-24.

56. Joshi M, Eagan J, Desai NK, Newton SA, Towne MC, Marinakis NS, Esteves KM, De Ferranti S, Bennett MJ, McIntyre A, et al. A compound heterozygous mutation in GPD1 causes hepatomegaly, steatohepatitis, and hypertriglyceridemia. Eur J Hum Genet. 2014;22(10):1229-32.

57. Basel-Vanagaite L, Zevit N, Har Zahav A, Guo L, Parathath S, PasmanikChor M, Mclntyre AD, Wang J, Albin-Kaplanski A, Hartman C, et al. Transient infantile hypertriglyceridemia, fatty liver, and hepatic fibrosis caused by mutated GPD1, encoding glycerol-3-phosphate dehydrogenase 1. Am J Hum Genet. 2012;90(1):49-60.

58. Guo XB, Deng X, Wei Y. Hematopoietic substrate-1-associated protein X-1 regulates the proliferation and apoptosis of endothelial progenitor cells through Akt pathway modulation. Stem Cells. 2018;36(3):406-19.

59. Suh HY, Choi H, Paeng JC, Cheon GJ, Chung JK, Kang KW. Comprehensive gene expression analysis for exploring the association between glucose metabolism and differentiation of thyroid cancer. BMC Cancer. 2019:19(1):1260.

60. Baumann U, Fernandez-Saiz V, Rudelius M, Lemeer S, Rad R, Knorn AM, Slawska J, Engel K, Jeremias I, Li ZL, et al. Disruption of the PRKCDFBXO25-HAX-1 axis attenuates the apoptotic response and drives lymphomagenesis. Nat Med. 2014;20(12):1401-9.

61. Arreola R, Valderrama B, Morante ML, Horjales E. Two mammalian glucosamine-6-phosphate deaminases: a structural and genetic study. FEBS Lett. 2003;551(1-3):63-70.

62. Zhang J, Zhang W, Zou D, Chen G, Wan T, Li N, Cao X. Cloning and functional characterization of GNPI2, a novel human homolog of glucosamine-6-phosphate isomerase/oscillin. J Cell Biochem. 2003;88(5):932-40.

63. Wolosker $\mathrm{H}$, Kline D, Bian Y, Blackshaw S, Cameron AM, Fralich TJ, Schnaar $\mathrm{RL}$, Snyder SH. Molecularly cloned mammalian glucosamine-6-phosphate deaminase localizes to transporting epithelium and lacks oscillin activity. FASEB J. 1998;12(1):91-9.

64. Li D, Cheng X, Zheng W, Chen J. Glucosamine-6-phosphate isomerase 1 promotes tumor progression and indicates poor prognosis in hepatocellular carcinoma. Cancer Manag Res. 2020;12:4923-35.

65. Oikari S, Makkonen K, Deen AJ, Tyni I, Karna R, Tammi RH, Tammi MI. Hexosamine biosynthesis in keratinocytes: roles of GFAT and GNPDA enzymes in the maintenance of UDP-GICNAc content and hyaluronan synthesis. Glycobiology. 2016;26(7):710-22.

66. Zhou W, Zhang S, Cai Z, Gao F, Deng W, Wen Y, Qiu ZW, Hou ZK, Chen XL. A glycolysis-related gene pairs signature predicts prognosis in patients with hepatocellular carcinoma. PeerJ. 2020;8:e9944.

67. Gu J, Zhang J, Huang W, Tao T, Huang Y, Yang L, Yang J, Fan Y, Wang H. Activating miRNA-mRNA network in gemcitabine-resistant pancreatic cancer cell associates with alteration of memory CD4(+) T cells. Ann Transl Med. 2020;8(6):279.

68. He YJ, Li WL, Liu BH, Dong H, Mou ZR, Wu YZ. Identification of differential proteins in colorectal cancer cells treated with caffeic acid phenethyl ester. World J Gastroenterol. 2014;20(33):11840-9.

69. Yang WL, Wei L, Huang WQ, Li R, Shen WY, Liu JY, Xu JM, Li B, Qin Y. Vigilin is overexpressed in hepatocellular carcinoma and is required for HCC cell proliferation and tumor growth. Oncol Rep. 2014;31(5):2328-34.

70. Gagne JP, Gagne P, Hunter JM, Bonicalzi ME, Lemay JF, Kelly I, Le Page C, Provencher D, Mes-Masson AM, Droit A, et al. Proteome profiling of human epithelial ovarian cancer cell line TOV-112D. Mol Cell Biochem. 2005;275(1-2):25-55.

71. Kim HY, Lubman DM. Micro-proteome analysis using micro-chromatofocusing in intact protein separations. J Chromatogr A. 2008;1194(1):3-10.

72. Kim NS, Hahn Y, Oh JH, Lee JY, Oh KJ, Kim JM, Park HS, Kim S, Song KS, Rho SM, et al. Gene cataloging and expression profiling in human gastric cancer cells by expressed sequence tags. Genomics. 2004;83(6):1024-45.

73. Miao Y, Li Q, Sun G, Wang L, Zhang D, Xu H, Xu Z. MiR-5683 suppresses glycolysis and proliferation through targeting pyruvate dehydrogenase kinase 4 in gastric cancer. Cancer Med. 2020;9(19):7231-43.

74. Zhihua Y, Yulin T, Yibo W, Wei D, Yin C, Jiahao X, Runqiu J, Xuezhong $X$. Hypoxia decreases macrophage glycolysis and M1 percentage by targeting microRNA-30c and mTOR in human gastric cancer. Cancer Sci. 2019;110(8):2368-77.

75. Chen D, Wang H, Chen J, Li Z, Li S, Hu Z, Huang S, Zhao Y, He X. MicroRNA129-5p Regulates Glycolysis And Cell Proliferation By Targeting The Glucose Transporter SLC2A3 in gastric cancer cells. Front Pharmacol. 2018;9:502.

76. Liu L, Wang Y, Bai R, Yang K, Tian Z. MiR-186 inhibited aerobic glycolysis in gastric cancer via HIF-1alpha regulation. Oncogenesis. 2016;5:e224.

77. Hong X, Xu Y, Qiu X, Zhu Y, Feng X, Ding Z, Zhang S, Zhong L, Zhuang Y, Su C, et al. MiR-448 promotes glycolytic metabolism of gastric cancer by downregulating KDM2B. Oncotarget. 2016;7(16):22092-102.

\section{Publisher's Note}

Springer Nature remains neutral with regard to jurisdictional claims in published maps and institutional affiliations.

Ready to submit your research? Choose BMC and benefit from

- fast, convenient online submission

- thorough peer review by experienced researchers in your field

- rapid publication on acceptance

- support for research data, including large and complex data types

- gold Open Access which fosters wider collaboration and increased citations

- maximum visibility for your research: over 100M website views per year

At BMC, research is always in progress.

Learn more biomedcentral.com/submissions 